\title{
BIOCOMBUSTÍVEIS A PARTIR DE ÓLEOS E GORDURAS: DESAFIOS TECNOLÓGICOS PARA VIABILIZÁ-LOS
}

Paulo A. Z. Suarez*, André L. F. Santos, Juliana P. Rodrigues e Melquizedeque B. Alves

Instituto de Química, Universidade de Brasília, CP 4478, 70910-970 Brasília - DF, Brasil

Recebido em 28/1/09; aceito em 3/3/09; publicado na web em 17/3/09

\begin{abstract}
OILS AND FATS BASED BIOFUELS: TECHNOLOGICAL CHALENDGES. Periodically, during petroleum shortage, fatty acids and their derivatives have been used as alternative fuels to those derived from petroleum. Different approaches have been proposed, including the use of neat fats and oils or their derivatives. Indeed, the utilization of biodiesel produced by alcoholysis of triacilglycerides or esterification of fatty acids, or hydrocarbons obtained from cracking of fatty materials were studied and used in several countries. Increasing concerns about energy security and climate changes have lead several countries, including Brazil, to start up biofuels programs. Different technologies are currently being developed in order to produce biofuels with economical feasibility. In this work are discussed alternative fatty raw-materials and processing technologies that are currently being studied in order to produce fuels suitable to sustainable substitute diesel fuel.
\end{abstract}

Keywords: biodiesel; pyrolysis; transesterification.

\section{INTRODUÇÃO}

A crise do petróleo que se instaurou nas últimas décadas, aliada ao aumento da demanda por combustíveis e à crescente preocupação com o meio ambiente, preconizou a busca por fontes alternativas de energia no Brasil e no mundo. ${ }^{1,2}$ As pesquisas têm se concentrado no desenvolvimento de novos insumos básicos, de caráter renovável, para a produção de combustíveis que possam substituir os derivados de petróleo, o que coloca a biomassa em um papel de destaque, em razão da sua natureza renovável, ampla disponibilidade, biodegradabilidade e baixo custo. ${ }^{3}$

Além do desenvolvimento científico e tecnológico, uma questão que permeia a utilização de biomassa para produzir combustível é o dilema entre a segurança alimentar e energética. Se, por um lado, Brasil e Estados Unidos incentivam a produção dos biocombustíveis chamados de primeira geração, tais como álcool e biodiesel, por outro lado diversos países e organismos internacionais mostram a preocupação no aumento da crise mundial dos alimentos, argumentando que ela foi agravada pelo deslocamento das áreas tradicionalmente utilizadas para o cultivo de alimentos para a produção de insumos destinados à indústria dos biocombustíveis.

No atual estado da arte é provável que em muitos países ocorra o deslocamento das áreas destinadas à produção de alimentos para que se possa produzir biocombustíveis, mas no Brasil há várias opções viáveis para que não haja tal problema. Por exemplo, pastagens já abandonadas pela agropecuária no Centro-oeste ou áreas degradadas da Amazônia poderiam servir, respectivamente, de terras para o plantio de cana-de-açúcar e palmáceas oleaginosas destinadas à produção dos biocombustíveis, sem prejudicar a produção de alimentos. Vale ressaltar, ainda, que o Brasil detém tecnologia altamente eficiente para a produção de etanol a partir da cana-de-açúcar. Segundo estimativa do IBGE, em 2008 todo o complexo da cana-de-açúcar ocupou apenas $13,35 \%$ da área utilizada para agricultura no Brasil, ${ }^{4}$ sendo suficiente para produzir o açúcar para abastecer o nosso consumo interno e exportação e suprir a nossa demanda crescente por etanol combustível.

Em suma, a realidade brasileira garante alguma tranquilidade no que diz respeito à disponibilidade de áreas para o cultivo de

\footnotetext{
*e-mail: psuarez@unb.br
}

matérias-primas dos biocombustíveis para abastecer o mercado local, mas a maioria dos países apresenta problemas potenciais de impacto na produção de alimentos. Esta conjuntura torna imperativo o desenvolvimento de novas tecnologias e a busca por matérias-primas alternativas no sentido de melhorar a produção energética e o potencial econômico em relação ao biodiesel ou ao álcool, dentro de um modelo sustentável e capaz de suprir a demanda por alimentos. Há um esforço mundial neste sentido que é compartilhado pelo Brasil porque, apesar de não haver aparente risco de segurança alimentar, o avanço tecnológico poderá permitir ao nosso país se firmar como um dos líderes mundiais na produção de biocombustíveis sem prejudicar a nossa produção de alimentos.

No que diz respeito às matérias-primas para a produção dos biocombustíveis de primeira geração (biodiesel e álcool), uma primeira idéia foi utilizar resíduos domésticos e agroindustriais de baixo valor agregado. As primeiras rotas alternativas a serem exploradas no Brasil, e que já estão em funcionamento comercial, foram o uso de óleos residuais de frituras ${ }^{5}$ e a esterificação de ácidos graxos, ${ }^{6}$ que permitem a produção de biodiesel utilizando passivos ambientais de residências ou restaurantes e das indústrias de processamento de óleos e gorduras. Menos adiantadas, existem também diversas pesquisas para obtenção de álcool a partir de resíduos celulósicos, principalmente utilizando bagaços e palhas oriundos do setor agroindustrial. Mais recentemente, diversos estudos têm reportado, na mídia e literatura especializada, o potencial de fontes oleaginosas não usuais, não raro consorciando oleaginosas perenes, como a macaúba e o pinhão-manso, com produção de gado e grãos, ou, ainda, o desenvolvimento de biorreatores para a produção de óleos a partir de algas.

As rotas de obtenção dos chamados biocombustíveis de segunda geração, tais como a produção de hidrocarbonetos a partir de materiais graxos, também têm sido investigadas. Os processos alternativos mais discutidos atualmente no Brasil são o craqueamento, o hidrocraqueamento (H-Bio) e o eletrocraqueamento. Estas rotas têm a vantagem de permitir o uso de insumos residuais de baixa pureza e baixo custo.

Neste trabalho pretende-se abordar questões relacionadas às tecnologias que estão sendo estudadas no sentido de produzir combustíveis alternativos passíveis de serem utilizados como substitutos ao diesel fóssil utilizando como matérias-primas ácidos graxos e seus derivados. 


\section{MATÉRIAS-PRIMAS ALTERNATIVAS}

Conforme o que foi discutido até aqui, há hoje um interessante debate sobre biocombustíveis sendo travado. De um lado, países como o Brasil e os Estados Unidos incentivam a produção destes em larga escala, defendendo a tese de que poderia ser esta uma alternativa economicamente viável de substituição dos combustíveis fósseis, além de minimizar problemas ambientais. Em contraponto, países como Cuba e Venezuela questionam se o aumento da produção de biocombustíveis não deslocaria a produção de áreas cultiváveis para a produção de alimentos, aumentando problemas sociais de fome na América Latina e outras regiões pobres do planeta. Portanto, um dos grandes desafios dos processos de produção de biocombustíveis é dispor de matérias-primas capazes de atender às expectativas dos programas energéticos sem impactar de forma significativa a produção de alimentos.

Na Tabela 1 existe um quadro comparativo entre as produtividades, por hectare, de diversas fontes de óleos e gorduras tradicionais e também de algas. ${ }^{7}$ Evidentemente, os dados relatados na ref. 7 e apresentados na Tabela 1 representam valores médios aceitos na literatura e não são absolutos, pois a produtividade de culturas agrícolas depende de inúmeros fatores, como clima, nutrientes no solo, irrigação, entre outros. Percebe-se claramente a partir desses dados que a soja possui uma produtividade muito baixa em lipídeos, demandando enormes quantidades de terra para suprir os mercados de biocombustíveis. No entanto, a soja corresponde hoje a aproximadamente $90 \%$ da produção brasileira de óleos, ${ }^{8}$ o que faz com que seja a matéria-prima preferencial da indústria de biodiesel. Conforme o Ministério das Minas e Energia, a participação do óleo de soja na produção de biodiesel no país cresceu em 2008 de $78 \%$ em janeiro para $85 \%$ em novembro..$^{9,10}$ No entanto, fica claro que o aumento na demanda por óleos para produção de biocombustíveis dificilmente poderá ser atendido pela soja ou outros cereais como milho ou canola, uma vez que demandaria uma larga extensão de terra agriculturável. Uma produtividade melhor é alcançada com o uso de palmáceas, tidas por muitos especialistas em produção agrícola como as únicas viáveis hoje para atender programas de biodiesel em larga escala com baixo impacto na produção de alimentos.

Tabela 1. Comparação de algumas fontes de matéria-prima para a produção de biodiesel. Adaptada da ref. 7

\begin{tabular}{lcc}
\hline Fonte de biodiesel & $\begin{array}{c}\text { Produtividadede óleo } \\
\left(\mathrm{L} \mathrm{ha}^{-1}\right)\end{array}$ & $\begin{array}{c}\text { Área necessária } \\
(\mathrm{Mha})^{\mathrm{a}}\end{array}$ \\
\hline Milho & 172 & 1540 \\
Soja & 446 & 594 \\
Canola & 1190 & 223 \\
Coco & 2689 & 99 \\
Óleo de palma & 5950 & 45 \\
Microalga $^{\mathrm{b}}$ & 136900 & 2 \\
Microalga $^{\mathrm{c}}$ & 58700 & 4,5 \\
\hline
\end{tabular}

${ }^{\mathrm{a}}$ Área suficiente para atender a 50\% da demanda de combustível nos EUA; ${ }^{\mathrm{b}}$ variedades com $70 \%$ óleo (por peso) na biomassa; ${ }^{\mathrm{c}}$ variedades com $30 \%$ óleo (por peso) na biomassa.

Dentre as alternativas para produção de óleos e gorduras a partir da agricultura, tem-se dado um destaque especial à família Jatropha, especialmente ao gênero Curcas, conhecido no Brasil como pinhão-manso. ${ }^{11}$ Esta planta, assim como outras espécies da família Jatropha, é ainda pouco conhecida, mas pelo fato de ser perene e de se adaptar muito bem em regiões semi-áridas tem sido apontada como ideal para a produção de óleos no nordeste brasileiro, utilizando a agricultura familiar. ${ }^{11}$ Apesar de ser ainda bastante controversa a produtividade destas espécies devido ao pouco estudo científico, vários pesquisadores garantem que se pode obter por hectare até 2200 litros de óleo ao ano. ${ }^{12}$

O cultivo de microalgas também é promissor para a produção de biocombustíveis. Além da alta produtividade (Tabela 1), inúmeras outras vantagens podem ser apontadas, ${ }^{7,13}$ tais como, um ciclo de vida de poucos dias, permitindo colheitas contínuas e diminuindo as necessidades de logística de armazenagem necessárias para o caso de culturas anuais e, a possibilidade de utilizar como insumo para a fotossíntese das algas o $\mathrm{CO}_{2}$ oriundo de empresas poluidoras, o que colabora para a diminuição das emissões que contribuem para o efeito estufa. No entanto, a produção industrial de óleos a partir de microalgas ainda apresenta uma série de problemas tecnológicos: ${ }^{13}$ existe sempre a possibilidade de ataque de cepas de algas ou outros microorganismos selvagens não produtores de óleos, ou que o produzem em menor quantidade ou com composição indesejada; necessidade de se manter constante os diversos parâmetros de processo, tais como temperatura, $\mathrm{pH}$ e concentração dos nutrientes, pois a alteração desses parâmetros pode levar a uma queda acentuada na produção e mesmo a uma morte total do cultivo; os nutrientes necessários para o crescimento das algas, além do $\mathrm{CO}_{2}$, são bastante caros; após o crescimento das algas, deve-se proceder à colheita, que significa separar esses organismos unicelulares e microscópicos do meio de cultura, não havendo ainda tecnologia adequada disponível para realizar essa operação em larga escala; após isolar as algas se deve extrair o óleo, sendo para isso necessário romper a parede celular das mesmas, não sendo possível utilizar os processos industriais usuais de extração; e, finalmente, o óleo produzido tem alto teor de água e de ácidos graxos livres, o que impede o seu uso direto em processos alcalinos tradicionais de obtenção de biodiesel (veja discussão sobre produção de biodiesel). Tais dificuldades fazem com que o custo de produção de óleo a partir do cultivo de algas seja hoje até 20 vezes superior ao custo a partir da soja, não havendo previsão para que nos próximos anos esta tecnologia possa ser usada em larga escala. ${ }^{13} \mathrm{Ou}$ seja, ainda falta muita pesquisa e desenvolvimento para viabilizar o processo de obtenção de óleo a partir de algas para abastecer a indústria de biodiesel.

Outras matérias-primas que têm sido apontadas para a obtenção de biodiesel são os materiais graxos residuais, tanto de origem doméstica quanto industrial. As gorduras animais resultantes, principalmente, do abate de gado, aves e suínos são matérias-primas mais disponíveis hoje e estão sendo usadas para a produção de biodiesel em escala comercial no Brasil. ${ }^{910}$ Essas gorduras são uma alternativa para o problema de equilíbrio entre a produção de alimentos e energia, e apresentam um custo mais competitivo do biocombustível em relação aos combustíveis fósseis. No Brasil sobram por ano cerca de 500 mil toneladas de gorduras provenientes do abate de animais. ${ }^{14}$ Deve-se destacar que muitas dessas gorduras não têm um fim comercial, resultando em um enorme passivo ambiental para os frigoríficos que a produzem. Outro exemplo são as gorduras residuais de fritura, ${ }^{5} \mathrm{de}$ origem doméstica ou restaurantes e indústrias de alimentos, e esgotos domésticos, cujas maiores limitações são organizar sistemas eficientes de coleta e purificação.

Diante das diversas fontes de óleos e gorduras com potencial para produzir um combustível que venha a substituir parcial ou totalmente o diesel fóssil, deve-se ter clareza que três aspectos possam ser atendidos: viabilidade técnica e econômica para a produção e obtenção do óleo ou gordura em escala suficiente para atender à demanda pelo biocombustível; viabilidade técnica e econômica para transformá-lo em biocombustível; e, garantias de que a qualidade do biocombustível 
produzido será compatível com o seu uso em motores veiculares ou estacionários. Caso um desses três aspectos não seja contemplado, certamente não se deve considerar a fonte como matéria-prima potencial para programas energéticos.

Os principais componentes de óleos e gorduras são os ácidos graxos que podem estar livres ou esterificados com glicerol nas formas de mono-, di- ou triacilglicerídeos. Também podem ser encontrados fosfatídeos, que são ésteres mistos de glicerina com ácidos graxos e o ácido fosfórico. Além dos compostos ácidos graxos e seus derivados, outros em menor quantidade, como esteróis, ceras, antioxidantes, vitaminas, também estão presentes, tornando os óleos e gorduras uma mistura bastante complexa. ${ }^{15}$ Obviamente, as propriedades físico-químicas e a reatividade dessas misturas variam enormemente em função da sua composição, o que irá definir a viabilidade técnica e econômica do seu uso como matéria-prima para a produção de um biocombustível e o uso do mesmo.

O uso da mamona, por exemplo, foi largamente incentivado no Brasil para a produção de biodiesel. Porém, após ocorrer um grande incentivo para a produção desta oleaginosa, o que levou agricultores de todas as regiões do país a iniciar o cultivo, viu-se que tanto o processo de produção do biodiesel era difícil quanto a qualidade do combustível obtido não era adequada, sendo praticamente abandonado seu uso industrial no Brasil. ${ }^{9}$ Esta característica se deve porque o óleo de mamona apresenta um grupo hidroxila na cadeia carbônica do ácido ricinoléico, que compõe cerca de $90 \%$ do óleo de mamona. Tal característica química promove uma maior viscosidade e densidade ao óleo e ao biodiesel, não atendendo às propriedades desejadas do biocombustível. ${ }^{16}$ Por outro lado, óleos ou gorduras muito insaturados (por exemplo, o óleo de tungue) ou pouco insaturados (por exemplo, o sebo de boi) também levam à produção de biodiesel com problemas de qualidade. No primeiro caso, o excesso de duplas ligações pode levar à polimerização pelo contato com o ar ou, quando aquecidos, à polimerização oxidativa do biodiesel, durante seu armazenamento ou uso. Já o excesso de cadeias completamente saturadas aumenta o ponto de fusão do combustível, o que limita o seu uso em regiões de clima temperado e frio. Cabe destacar que estes problemas muitas vezes podem ser contornados com o uso de aditivos, por exemplo, antioxidantes, ${ }^{17}$ ou utilização de misturas de duas ou mais matériasprimas de forma a obter misturas com propriedades que melhoram tanto o seu processamento para gerar o biocombustível ${ }^{18}$ quanto as propriedades finais do mesmo. ${ }^{19}$

Outros exemplos que corroboram a necessidade de se avaliar a viabilidade técnica e econômica e a qualidade do biocombustível obtido são os insumos produzidos a partir de palmáceas, Jatropha, algas e gorduras residuais, os quais possuem alto teor de ácidos graxos livres. Estes altos teores ácidos impedem o seu uso direto em processos alcalinos tradicionais de obtenção de biodiesel (veja discussão sobre produção de biodiesel), necessitando processos prévios de purificação, o que pode muitas vezes inviabilizar economicamente o seu uso.

\section{ALTERNATIVAS DE PROCESSO}

\section{Processos de obtenção de ésteres metílicos e etílicos de ácidos graxos: biodiesel}

A principal tecnologia para obtenção de biodiesel no Brasil e no mundo é a transesterificação (ou alcoólise) alcalina homogênea de óleos e gorduras. Nessa reação, o óleo ou gordura, que são compostos basicamente de tri-ésteres da glicerina com ácidos graxos, é misturado a metanol ou etanol e, na presença de um catalisador, dá origem a uma mistura de ésteres metílicos ou etílicos de ácidos graxos e glicerina, conforme ilustrado na Figura $1 .{ }^{20}$ Essa mistura de ésteres metílicos ou etílicos é o que hoje se conhece como biodiesel. A reação de transesterificação é bem estudada e estabelecida principalmente utilizando-se catalisadores ácidos ou básicos de Bronsted. Os catalisadores básicos, principalmente soda cáustica ou outras bases fortes, tornaram-se dominantes principalmente devido aos seus baixos custos e rapidez do processo. ${ }^{21,22}$

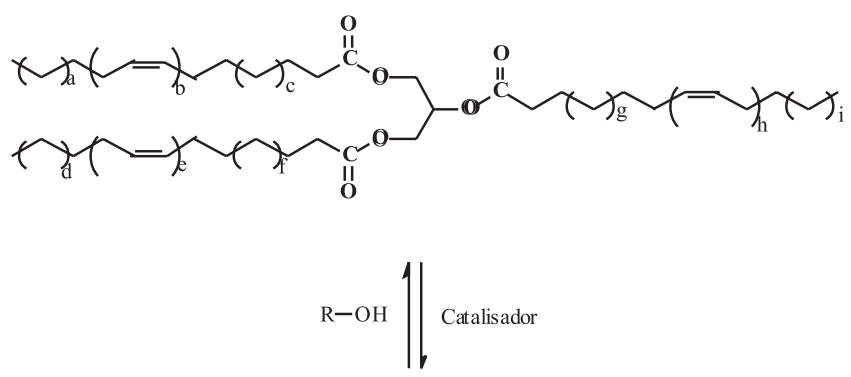

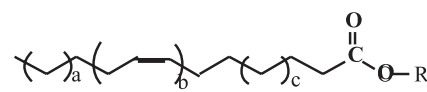

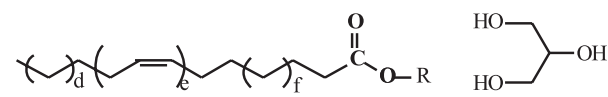

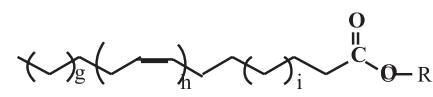

Figura 1. Reação de transesterificação ou alcoólise de triacilglicerídeos. Observações: (i) esta reação ocorre em sucessivas etapas onde di- e monoacilglicerídeos são formados, as quais foram omitidas para simplificar a figura; (ii) dependendo da fonte do óleo ou da gordura existe variação no numero de carbonos, que geralmente é um numero par, e de insaturações das cadeias alquídicas

Porém, o processo de transesterificação alcalina homogênea requer matérias-primas de alta pureza, praticamente isentas de ácidos graxos livres, fosfatídeos e água, o que significa uma limitação e pode comprometer o futuro da hegemonia dessa tecnologia. De fato, os ácidos graxos e fosfatídeos reagem rapidamente com catalisadores básicos tradicionais levando à formação de sabões e ao consumo de parte do catalisador. Para garantir uma eficiência catalítica torna-se necessário um excesso deste, contudo permanece a dificuldade da separação da glicerina e do biodiesel ao final do processo. ${ }^{23,24}$ Essa separação pode até mesmo ser inviabilizada ou tornada mais onerosa devido à lavagem e purificação. Por outro lado, a presença de água favorece também a reação de hidrólise dos ésteres presentes e dos glicerídeos formando ácidos graxos que, por sua vez, consomem catalisador e formam mais sabão. ${ }^{3}$ Como existem no processo diversas reações reversíveis em equilíbrio, ${ }^{25}$ uma solução para este problema seria a adição de grandes excessos de álcool e catalisadores, porém isto só é possível para teores não muito altos de impurezas, além de encarecer o processo de produção de biodiesel. ${ }^{3}$ Assim, o uso de óleos e gorduras brutas ou álcool hidratado, algo extremamente desejável a fim de tornar o processo mais barato, torna-se impossível pela rota alcalina tradicional, pois seria muito difícil obter um biodiesel em conformidade com as especificações exigidas pela Agência Nacional do Petróleo, Gás Natural e Biocombustíveis - ANP. ${ }^{26}$

Por estas razões, nas últimas duas décadas intensificaram-se os estudos no sentido de encontrar catalisadores alternativos, que possibilitem aperfeiçoar os processos industriais de alcoólise de triacilglicerídeos. ${ }^{27} \mathrm{O}$ principal objetivo desses estudos é encontrar um processo onde as espécies cataliticamente ativas possuam menor sensibilidade à presença de ácidos graxos livres e água, facilitando a 
separação e purificação dos produtos no final da reação e possibilitando a recuperação e reutilização dos catalisadores. Como alternativa aos catalisadores básicos tradicionais, diversas novas classes foram propostas, tais como enzimas, bases orgânicas, complexos metálicos, aluminossilicatos e óxidos metálicos, sendo estes estudos recentemente discutidos em artigo de revisão. ${ }^{3}$ A principal vantagem destas novas classes de catalisadores é o fato deles não formarem sabões na presença de ácidos graxos livres e fosfolipídios, o que facilita a separação dos produtos no final da alcoólise. Alguns deles ainda são facilmente recuperáveis e reutilizáveis.

Outra proposta para transformar matérias-primas com altos teores de ácidos graxos em biodiesel é utilizar a reação de esterificação destes ácidos com metanol ou etanol, conforme representado na Figura 2. ${ }^{28}$ Diversos trabalhos da literatura descrevem sistemas para a esterificação de ácidos graxos baseados em precursores catalíticos ácidos de Bronsted ou de Lewis em condições homogêneas, bifásicas e heterogêneas. ${ }^{23,24,28-35}$ Os catalisadores homogêneos, geralmente ácidos minerais fortes, estão associados a problemas de corrosão de equipamentos e a dificuldades de separação dos produtos. Já os catalisadores heterogêneos possuem baixa performance por restrições no processo de transferência de fase. Tais limitações impulsionam a pesquisa e o desenvolvimento de sistemas catalíticos que possuam alta atividade, fácil recuperação e evitem a corrosão dos equipamentos.

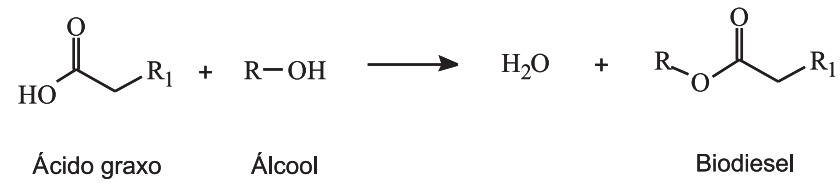

Figura 2. Reação de esterificação de ácidos graxos

No Brasil, a esterificação é utilizada em escala industrial em um processo desenvolvido pela empresa Agropalma em parceria com a Universidade Federal do Rio de Janeiro. Este processo utiliza catalisadores sólidos com acidez de Bronsted e Lewis, como zeólitas e materiais com zircônio e alumínio, para obtenção de biodiesel a partir de resíduos de baixo valor. ${ }^{6}$ Os catalisadores mostraram-se ativos para a esterificação de uma mistura obtida após o refino do óleo de palma contendo $80 \%$ de ácido graxo livre. Industrialmente é utilizado óxido de nióbio hidratado como catalisador. $\mathrm{O}$ processo está representado na Figura 3.

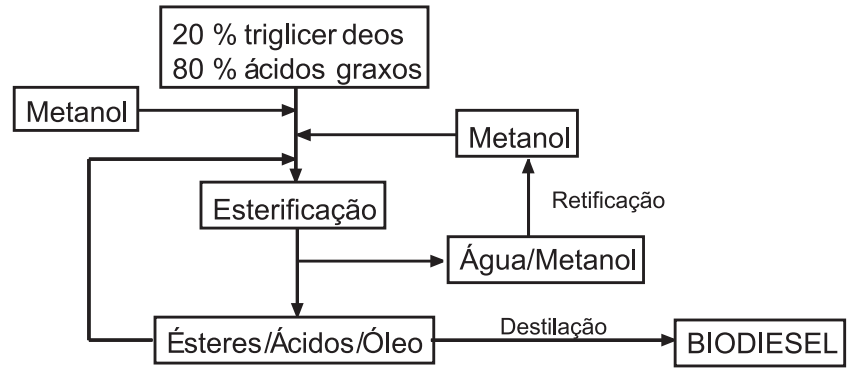

Figura 3. Processo comercial de obtenção de biodiesel por esterificação de um coproduto ácido gerado durante a neutralização de óleo de palma

Entretanto, se por um lado há uma desvantagem em converter um substrato rico em ácidos graxos via transesterificação devido à formação de emulsões, por outro este mesmo substrato também não é ideal para a esterificação direta, agora pela presença dos triacilglicerídeos. Cabe ressaltar que a transesterificação promovida por catalisadores ácidos de Bronsted é mais lenta que a de esterificação. Assim, o produto final do processo contém altos teores de triglicerídeos, sendo necessário destilar a mistura à baixa pressão e alta temperatura, para purificar o biodiesel.

Uma alternativa para este tipo de substrato é promover previamente uma reação de hidrólise seguida pela esterificação dos ácidos graxos obtidos. O processo de hidroesterificação, hidrólise seguida de esterificação, favorece a utilização de matérias-primas de qualquer teor de ácidos graxos e umidade: óleos de plantas oleaginosas, resíduos gordurosos industriais, óleos de frituras, subprodutos de refino de óleos vegetais. Tradicionalmente, os ácidos graxos são obtidos pela saponificação de óleos ou gorduras com hidróxidos de sódio ou potássio, seguida pela acidificação com ácido mineral, usualmente ácido sulfúrico.

A reação de hidrólise acontece na fase orgânica por meio de três etapas consecutivas e reversíveis, nas quais são formados diacilglicerídeos e monoacilglicerídeos como intermediários, resultando em uma molécula de ácido graxo em cada etapa. $\mathrm{Na}$ indústria, existem dois procedimentos mais difundidos, os quais utilizam catalisadores ácidos. O primeiro é realizado em autoclave ou em reator tubular contínuo, no qual se utilizam pressões em torno de 100-7000 kPa e temperaturas de 100 a $360^{\circ} \mathrm{C}$, sendo necessário catalisadores como os óxidos de zinco e cálcio quando a temperatura é inferior a $200{ }^{\circ} \mathrm{C} .{ }^{36} \mathrm{Já}$ o segundo, processo Twitchell, ocorre à temperatura de $100^{\circ} \mathrm{C}$, pressão atmosférica, meio ácido e um catalisador de transferência de fase como os ácidos alqui-aril-sulfônicos ou cicloalifático-sulfônicos. ${ }^{36-38}$ Algumas melhorias para acelerar o processo Twitchell têm sido relatadas, como o uso diretamente de catalisadores de transferência de fase, tanto em meio ácido como básico, ou o uso destes com aplicação de ultrassom..$^{39,40}$

Trabalhos mais recentes revelaram que a hidrólise de óleos e gorduras pode ser catalisada por enzimas, mais especificamente por lipases. ${ }^{41-43}$ Ting et al. demonstraram que essas enzimas apresentam atividades tanto se colocadas livres no meio reacional como imobilizadas em algum polímero ou gel e não há a necessidade de altas temperaturas e nem de altas pressões. ${ }^{43}$ Também tem sido estudada a hidrólise em condições supercríticas. A água em estado supercrítico apresentou bons resultados, além de ser considerada uma rota limpa, pois não utiliza solvente nem catalisadores que podem ser nocivos ao meio ambiente. ${ }^{44,45}$ Foi ainda reportado o uso de $\mathrm{CO}_{2}$ supercrítico como solvente, sendo observado que este possui as mesmas vantagens da água supercrítica e ainda facilita o processo de separação dos ácidos graxos dos outros produtos. ${ }^{46}$

\section{Processos de obtenção de hidrocarbonetos: bio-óleo}

A reação de craqueamento de triacilglicerídeos consiste na quebra de ligações envolvendo os grupos funcionais éster e, em menor grau, as cadeias carbônicas dos triésteres componentes dos óleos e gorduras formando uma mistura de compostos constituída principalmente de hidrocarbonetos e, em menor quantidade, compostos oxigenados. ${ }^{3}$ A Figura 4 mostra um esquema geral da reação de craquamento de óleos e gorduras.

A reação de craqueamento ocorre a temperaturas superiores a $350{ }^{\circ} \mathrm{C}$, na presença ou ausência de catalisadores, em diversas etapas distintas e consecutivas. ${ }^{47-49} \mathrm{Na}$ primeira etapa, mostrada na reação 1 da Figura 5, que é chamada craqueamento primário, são formadas duas moléculas de ácidos carboxílicos, uma molécula de ceteno e acroleína. A mistura formada é extremamente instável nas condições reacionais e reage rapidamente, conforme mostrado na reação 2 da Figura 5, formando novos ácidos carboxílicos, hidrocarbonetos, aldeídos e cetonas. Numa segunda etapa de craqueamento, chamada de craqueamento secundário, verifica-se a desoxigenação dos produtos formados no craqueamento primário, principalmente os ácidos carboxílicos. De fato, os ácidos carboxílicos formados durante o 


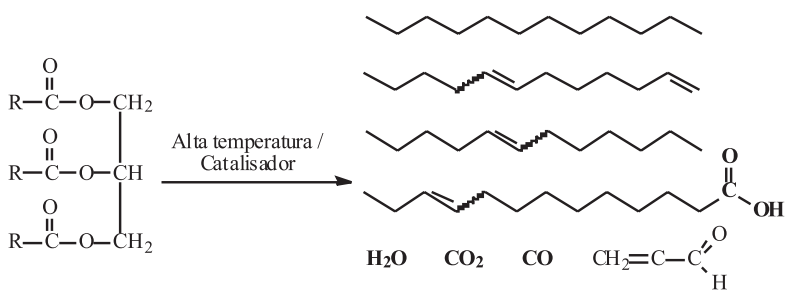

Figura 4. Reação de craqueamento de triacilglicerídeos. Note que devido à complexidade das reações foram colocados apenas exemplos ilustrativos, sendo ilustrados os principais produtos obtidos

craqueamento primário e reações de rearranjo são desoxigenados no craqueamento secundário, que pode ocorrer por duas rotas distintas: descarboxilação e descarbonilação, conforme mostrado nas reações 3 e 4 da Figura $5 .{ }^{50}$ Posteriormente, podem ocorrer inúmeras reações consecutivas, tais como rearranjos, craqueamento das cadeias carbonílicas, acoplamentos radicalares, entre outras. Existem trabalhos na literatura que demonstram que os produtos finais do craqueamento dependem de diversos fatores, tais como a composição química da matéria-prima utilizada, temperatura do processo, tempo de residência, presença e de catalisadores e vapor. ${ }^{51,52}$<smiles></smiles>

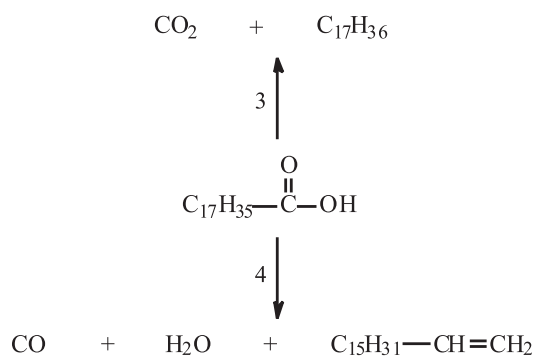

Figura 5. Algumas reações que ocorrem durante o processo de craqueamento. Note que devido à complexidade das reações foram colocados apenas exemplos ilustrativos, pois mais de 500 produtos podem ser formados durante o craqueamento de um triglicerídeo simples

Recentemente, foi mostrado que apenas com destilação dos produtos obtidos pelo craqueamento térmico, sem uso de catalisadores, é possível isolar um biocombustível que satisfaz os parâmetros exigidos para o diesel de petróleo, mostrando que o produto craqueado poderia ser utilizado diretamente nos motores, sem a necessidade de modificações. ${ }^{53}$ Posteriormente, diversos estudos foram realizados com este combustível de forma a analisar outras propriedades não especificadas pela ANP, como poder calorífico,${ }^{54}$ lubricidade, ${ }^{55}$ tensão superficial, ${ }^{56}$ estabilidade térmica e química, ${ }^{57}$ poder tensoativo, sendo observado que ele possui propriedades semelhantes às do diesel fóssil. No entanto, o produto formado apresenta uma alta acidez devido à presença de ácidos graxos. Apesar da corrosividade ao cobre não superar à do diesel nos testes realizados, ${ }^{57}$ testes de longo prazo em motores são ainda necessários para se definir se o produto pode ou não ser usado em máquinas convencionais.

No sentido de alterar a seletividade dos produtos do craqueamento de óleos e gorduras, além da variação de temperatura, diferentes estratégias têm sido adotadas, como o uso de vapor de água ou de catalisadores heterogêneos. Durante o craqueamento de óleo de canola na presença de vapor de água, foi verificado que a hidrólise dos triacilglicerídeos para a formação de ácidos graxos foi facilitada, ${ }^{19}$ mas ocorreu também uma inibição na etapa de decomposição destes para a formação de hidrocarbonetos. Por outro lado, a estratégia do uso de catalisadores heterogêneos vem demonstrando que catalisadores sólidos que apresentam acidez de Lewis, como aluminossilicatos e óxidos, são eficientes para promover a desoxigenação dos produtos, sendo a seletividade dos produtos dependente da natureza do sólido utilizado. Por exemplo, a desoxigenação dos produtos da decomposição térmica de óleo de soja é favorecida quando a reação é realizada na presença de diferentes zeólitas, ${ }^{58-60}$ sendo também observado que reações de craqueamento da cadeia dos hidrocarbonetos formados, ciclizações e aromatização levam à formação de um produto próximo à faixa da gasolina (8-10 carbonos). Já aluminossilicatos não estruturados e ( $\gamma$-alumina $)^{61,62}$ são também eficientes na desoxigenação dos produtos formados, diminuindo as reações de craqueamento da cadeia carbônica e de ciclização e aromatização, gerando um biocombustível com perfil de destilação próximo ao do diesel. Por outro lado, foi relatado que alguns catalisadores, como óxidos básicos $\mathrm{MgO}$ e $\mathrm{CaO}^{59}$ ou $\mathrm{Nb}_{2} \mathrm{O}_{5}{ }^{63}$ e alguns derivados, ${ }^{64}$ estabilizam os ácidos carboxílicos formados levando a produtos com acidez superior à verificada no craqueamento térmico.

No Brasil, uma miniusina para craqueamento de óleos e gorduras em pequena escala foi desenvolvida visando a autossuficiência energética de fazendas e comunidades isoladas. ${ }^{65}$ Nesta usina óleos ou gorduras são craqueados e posteriormente destilados em regime contínuo, gerando produtos que atendem às especificações do diesel de petróleo.

O processo de obtenção de hidrocarbonetos a partir de óleos e gorduras sob altas pressões de hidrogênio e na presença de catalisadores é chamado de hidrocraqueamento. Um esquema da reação de hidrocraqueamento de óleos e gorduras é mostrado na Figura 6. O hidrocraqueamento de óleos vegetais ainda é pouco estudado e praticamente não existem trabalhos na literatura aberta com estudos detalhados deste processo. Um dos poucos artigos disponíveis refere-se a um estudo do hidrocraqueamento de óleos de babaçu e de soja na presença de $\mathrm{Ni} / \mathrm{SiO}_{2}$ e sulfetos de $\mathrm{Ni}-\mathrm{Mo} / \gamma-\mathrm{Al}_{2} \mathrm{O}_{3}{ }^{50} \mathrm{Nesse}$ trabalho, além de serem feitos diversos estudos termodinâmicos da reação, concluiu-se que o hidrocraqueamento de óleos pode ser uma alternativa viável para a produção de combustíveis sucedâneos ao petróleo, pois que a pirólise dos óleos de babaçu e de soja na presença de hidrogênio molecular levou à formação quase que exclusiva de hidrocarbonetos.

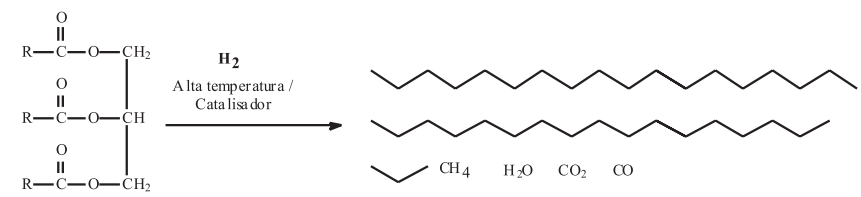

Figura 6. Reação de hidrocraqueamento de triacilglicerídeos. Note que devido à complexidade das reações foram colocados apenas exemplos ilustrativos, sendo ilustrados os principais produtos obtidos 
Devido à grande similaridade do hidrocraqueamento com a dessulfurização de diesel utilizado nas refinarias de petróleo, a Petrobras desenvolveu o processo $\mathrm{H}-\mathrm{BIO} .{ }^{66}$ Este processo consiste basicamente na mistura de óleos ou gorduras com correntes de diesel que passam pelo reator de dessulfurização, formando um diesel de excelente qualidade.

Outro processo alternativo, passível de ser empregado com o intuito de viabilizar a utilização de óleos e gorduras como insumos combustíveis, baseia-se em uma reação conhecida como descarboxilação anódica de triacilglicerídeos e derivados ou eletrocraqueamento. Esta reação, muitas vezes chamada apenas eletrólise de Kolbe, é muito estudada e conhecida em eletrossíntese orgânica, porém pouco empregada para fins tecnológicos, em especial na obtenção de substitutos aos hidrocarbonetos fósseis como fontes alternativas de energia. Apesar de Faraday haver realizado a eletrólise de soluções aquosas de acetatos em 1834, foi Kolbe, em 1849, quem reconheceu a reação e a aplicou à síntese de uma série de hidrocarbonetos. ${ }^{67}$ Esta reação é um método eficiente na geração de radicais para fins sintéticos e bastante utilizada em síntese orgânica. ${ }^{68} \mathrm{~A}$ eletrólise de Kolbe é definida como a oxidação eletroquímica de um elétron de íons carboxilatos, que podem ser obtidos a partir de ácidos carboxílicos ou ésteres, com subsequente descarboxilação, ${ }^{69}$ levando a radicais que se dimerizam em produtos de homoacoplamento, de acordo com a Figura 7.

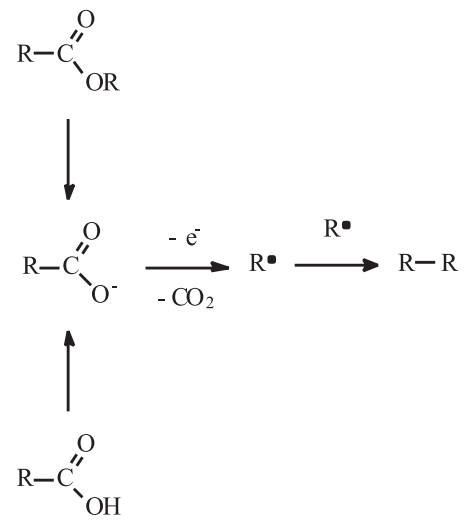

Figura 7. Esquema da eletrólise de Kolbe. Note que devido à complexidade das reações foram colocados apenas exemplos ilustrativos, sendo ilustrados os principais produtos obtidos

Em relação aos ácidos graxos e seus derivados, sabe-se que é possível descarboxilá-los por meio da oxidação anódica. Para tal, podem ser usados óleos ou gorduras, que devem ser previamente saponificados, ou resíduos (borras) ácidos ou básicos obtidos em processos agroindustriais. Na Figura 8 apresenta-se um esquema do eletrocraqueamento de um triacilglicerídeo com ácidos graxos usuais com 18 carbonos em sua cadeia. Nota-se que a oxidação dos íons carboxilato derivados desse triacilglicerídeo irá formar radicais com 17 carbonos, os quais irão se acoplar levando a hidrocarbonetos com 34 carbonos, com ou sem insaturações. Se for considerado que óleos e gorduras naturais são misturas complexas contendo ácidos graxos com cadeias alquídicas na faixa entre 12 a 24 carbonos, conclui-se que os dímeros formados terão entre 22 e 46 átomos de carbono na cadeia. Assim, a reação acaba fornecendo como produtos misturas de hidrocarbonetos sólidas à temperatura ambiente, que não podem ser utilizadas diretamente em motores à combustão, sendo necessários posteriores processos de craqueamento e destilação para se obter um biocombustível líquido que possa substituir o diesel fóssil.

Contudo, para evitar a necessidade de craqueamento dos produtos formados, pode-se efetuar a eletrólise de Kolbe na presença de outras
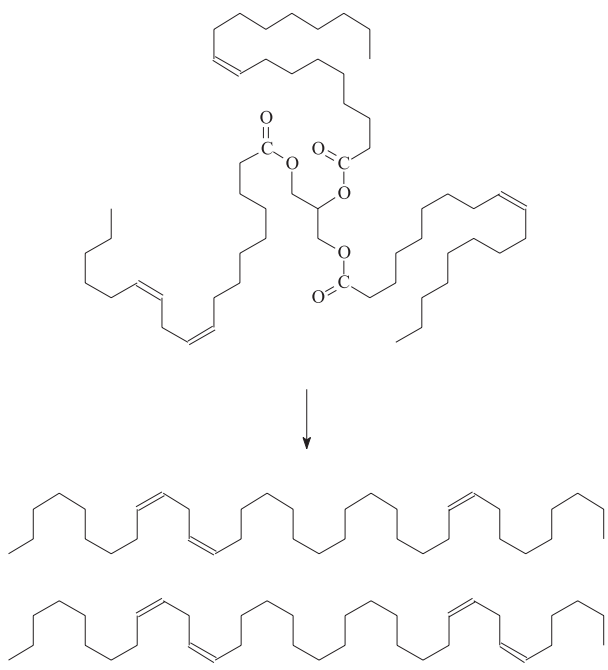

Figura 8. Produtos da reação direta de Kolbe de triacilglicerídeos. Note que devido à complexidade das reações foram colocados apenas exemplos ilustrativos, sendo ilustrados os principais produtos obtidos

espécies que possam ser oxidadas, como acetatos (Figura 9). Assim, serão formados radicais com tamanhos diferentes, levando a uma mistura de produtos com tamanhos de cadeia pequenos, médios e longos. A formação de produtos com cadeias longas pode ser regulada pela presença de um excesso de acetatos no meio reacional, para suprimir a formação de tais espécies químicas. Assim, pode-se obter uma mistura com propriedades físico-químicas muito próximas às do diesel, podendo ser utilizadas diretamente como biocombustível em motores convencionais.
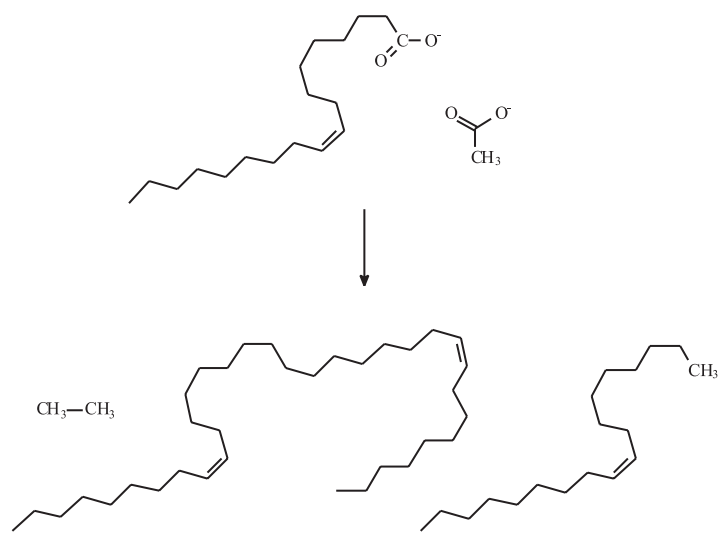

Figura 9. Representação esquemática da eletrólise de Kolbe de uma mistura de acetato e oleato. Note que devido à complexidade das reações foram colocados apenas exemplos ilustrativos, sendo ilustrados os principais produtos obtidos

\section{CONSIDERAÇÕES FINAIS}

Suprir o mercado de combustíveis com matérias-primas de origem biológica é um importante desafio para aumentar a presença de biocombustíveis na matriz energética mundial. No que diz respeito a biocombustíveis produzidos a partir de ácidos graxos e derivados este desafio é ainda maior, tendo em vista a baixa produtividade que as culturas oleaginosas tradicionais possuem. No entanto, diversas alternativas tanto de produção dos óleos e gorduras como de processamento dos mesmos estão sendo hoje estudadas, as quais apontam que provavelmente não haverá uma solução energética única, mas que deverá haver uma diversidade tanto de matérias-primas quanto de processos e de combustíveis. 
Os processos de obtenção de hidrocarbonetos a partir de materiais graxos parecem ser extremamente atraentes, pois demandam poucos insumos e podem ser realizados a partir de materiais residuais de baixo valor agregado e mesmo de passivos ambientais da agroindústria. No entanto, ainda existem entraves para a comercialização desses biocombustíveis, já que não existe atualmente no Brasil especificação para os hidrocarbonetos obtidos a partir de biomassa. De fato, a ANP restringe o uso de hidrocarbonetos para aqueles que sejam obtidos a partir do petróleo ou gás natural, proibindo a comercialização daqueles obtidos a partir de outras fontes, mesmo que possuam composição química semelhante ou idêntica àquela obtida a partir de uma matéria-prima fóssil. ${ }^{70}$ Porém, isso não impede que num futuro próximo estes combustíveis entrem na matriz energética brasileira. Há grandes pressões mundiais para que novas tecnologias sejam incluídas na produção de biocombustíveis, e expectativas para que essas tecnologias possam vir a substituir os chamados biocombustíveis de Primeira Geração.

\section{AGRADECIMENTOS}

Aos apoios financeiros que os autores vêm recebendo de diversas instituições para o desenvolvimento de pesquisas em oleoquímica, tais como FINEP, CNPq, CTPETRO, CTEnerg, MCT, MDA, FBB, FAPDF, FINATEC e DPP-UnB. Os autores agradecem, também, as bolsas de pesquisa CNPq.

\section{REFERÊNCIAS}

1. Pousa, G. P. A. G.; Santos, A. L. F.; Suarez, P. A. Z.; Energy Policy 2007, 35, 5393.

2. Suarez, P. A. Z.; Meneghetti, S. M. P.; Quim. Nova 2007, 30, 2068.

3. Suarez, P. A. Z.; Meneghetti, S. M. P.; Meneghetti, M. R.; Wolf, C. R.; Quim. Nova 2007, 30, 667.

4. http://www.ibge.gov.br/home/estatistica/indicadores/agropecuaria/lspa/ 1spa_200812_1.shtm, acessada em Janeiro 2009.

5. Costa Neto, P. R.; Rossi, L. F. S.; Zagonel, G. F.; Ramos, L. P.; Quim. Nova 2000, 23, 537.

6. Aranda, D. A.G.; Antunes, O.A.C.; WO pat. 20040969622004.

7. Chisti, Y.; Biotech. Adv. 2007, 25, 294.

8. http://www.abiove.com.br/palestras/abiove_pal_biodiesel_01jun06.pdf, acessada em Janeiro 2009.

9. Freitas, R. C.; Biodieselbr 2008, 7, 52.

10. http://www.biodieselbr.com/noticias/bio/governo-informa-materiasprimas-usinas-13-01-09.htm, acessada em Janeiro 2009.

11. Oliveira, J. S.; Leite, P. M.; DeSouza, L. B. Mello, V. M.; Silva, E. C.; Rubim, J. C.; Meneghetti, S. M. P.; Suarez, P. A. Z.; Biomass Bioenerg. 2009, 33, 449.

12. Duarte, A.; Biodieselbr 2008, 5, 32.

13. Torrey, M.; Tribology \& Lubrication Tech. 2008, 64, 26.

14. Bellaver, C.; Revista Biodiesel 2008, 26, 17.

15. Moretto, E.; Tecnologia de óleos e gorduras vegetais na indústria de alimentos, Varela: São Paulo, 1998.

16. Suarez, P. A. Z.; Meneghetti, S. M. P.; Ferreira, V. F.; Quim. Nova 2006, 29, 1157.

17. Domingos, A. K.; Vecchiatto, W.; Wilhelm, H. M.; Ramos, L. P.; J. Braz. Chem. Soc. 2007, 18, 416.

18. Meneghetti, S. M. P.; Meneghetti, M. R.; Serra, T. A.; Barbosa, D. C.; Wolf, C. R.; Energy \& Fuels 2007, 21, 3746.

19. Moser, B. R.; Energy \& Fuels 2008, 22, 4301.

20. Suarez, P. A. Z.; Abreu, F. R.; Lima, D. G.; Hamú, E. H.; Wolf, C. R.; J. Mol. Catal. A: Chem. 2004, 209, 29.

21. Pinto, A. C.; Guarieiro, L. L. N.; Rezende, M. J. C.; Ribeiro, N. M.; Torres, E. A.; Lopes, W. A.; Pereira, P. A.; de Andrade, J. B.; J. Braz. Chem. Soc. 2005, 16, 1313.
22. Lang, X.; Dalai, A. K.; Bakhshi, N. N.; Reaney, M. J.; Hertz, P. B.; Bioresour. Technol. 2001, 80, 62.

23. Marchetti, J. M.; Miguel, V. U.; Errazu, A. F.; Fuel 2007, 86, 906.

24. Kusdiana, D.; Saka, S.; J. Chem. Eng. Jpn. 2001, 34, 383.

25. Schuchardt, U.; Sercheli, R.; Vargas, R. M.; J. Braz. Chem. Soc. 1998, 9, 199.

26. Resolução ANP No 7, de 19/03/2008, Diário Oficial da União, 20/03/2008.

27. Macedo, C. C. S.; Abreu, F. R.; Tavares, A. P.; Alves, M. B.; Zara, L. F.; Rubim J. C.; Suarez, P. A. Z.; J. Braz. Chem. Soc. 2006, 17, 1291.

28. Keim, G. I.; US pat. 2,383-601 1945 (CA 40, 4617).

29. Jackson, M. A.; Mbaraka, I. K.; Shanks, B. H.; Appl. Catal. A 2006, 310, 48.

30. Kiss, A. A.; Omota, F.; Dimian, A. C.; Rothenberg G.; Top. Catal. 2006, 40,141 .

31. Minami, E.; Saka, S.; Fuel 2006, 85, 2479.

32. Mbaraka, I. K.; Shanks, B. H.; J. Catal. 2005, 229, 365.

33. Tesser, R.; Di Serio, M.; Guida, M.; Nastasi, M.; Santacesaria, E.; Ind. Eng. Chem. Res. 2005, 44, 7978.

34. Brito, Y. C.; Mello, V. M.; Macedo, C. C. S.; Meneghetti, M. R.; Suarez, P. A. Z.; Meneghetti, S. M. P.; Appl. Catal. A 2008, 351, 24.

35. Neto, B. A. D.; Alves, M. B.; Lapis, A. A. M.; Nachtigall, F. M.; Eberlin, M. N.; Dupont, J.; Suarez, P. A. Z.; J. Catal. 2007, 249, 152.

36. Shreve, R. N.; Brink, J. A.; Chemical Process Industries, $4^{\text {th }}$ ed., McGraw-Hill: Washington, 1997, p. 425.

37. Patil, T. A.; Butala, D. N.; Kaghunathan, T. S.; Shankar, H. S.; Ind. Eng. Chem. Res. 1988, 27, 727.

38. Lascaray, L.; Ind. Eng. Chem. 1949, 41, 786.

39. Bhatkhande, B. S.; Samant, S. D.; Ultrasonics Sonochemistry 1998, 5, 7.

40. Entezari, M. H.; Keshavarzi, A.; Ultrasonics Sonochemistry 2001, 8, 213.

41. Freitas, L.; Bueno, T.; Perez, V. H.; Santos, J. C.; de Castro, H. F.; World J. Microbiol. Biotechnol. 2007, 23, 1725.

42. Noureddini, H.; Gao, X.; Joshi, S.; J. Am. Oil Chem. Soc. 2003, 80, 1077.

43. Ting, W. J.; Tung, K. Y.; Giridhar, R.; Wu, W. T.; J. Mol. Catal. B: Enzim. 2006, 42, 32.

44. King, J. W.; Holliday, R. L.; List, G. R.; Green Chem. 1999, 1, 261.

45. Holliday, R. L.; King, J. W.; List, G. R.; Ind. Eng. Chem. Res. 1997, 36, 932.

46. Moquin, P. H. L.; Temelli, F.; J. Supercritical Fluids 2008, 45, 94

47. Idem, R. O.; Katikaneni, S. P. R.; Bakhshi, N. N.; Energy \& Fuels 1996, 10,1150 .

48. Vonghia, E.; Boocock, D. G. B.; Konar, S. K.; Leung, A.; Energy \& Fuels 1995, 9, 1090.

49. Landis, P. S.; Craver, R. H.; Barton, D. E.; J. Agric. Food Chem. 1992, $40,456$.

50. Gusmão, J.; Brodzki, D.; Djéga-Mariadassou, G.; Fretty, R.; Catalysis Today 1989, 5, 533.

51. Sensaz, S.; Kaynar, I.; Ind. Crops Produc. 2006, 23, 99.

52. Uzun, B. B.; Putun, A. E.; Putun, E.; Bioresour. Technol. 2006, 97, 569.

53. Soares, V. C. D.; Lima, D. G. de; Ribeiro, E. B; Carvalho, D. A.; Cardoso, E. C. V.; Rassi, F. C.; Mundim, K. C.; Rubim, J. C.; Suarez, P. A. Z.; J. Anal. Appl. Pyrol. 2004, 71, 987.

54. DeOliveira, E.; Quirino, R. L.; Suarez, P. A. Z.; Prado, A. G. S.; Thermochim. Acta 2006, 450, 87.

55. Suarez, P. A. Z.; Moser, B. R.; Sharma, B. K.; Erhan, S. Z.; Fuel 2009, $88,1143$.

56. Doll, K. A.; Sharma, B. K.; Suarez, P. A. Z.; Erhan, S. Z.; Energy \& Fuels 2008, 22, 2061.

57. Sharma, B. K.; Suarez, P. A. Z.; Perez, J. M.; Erhan, S. Z.; submetido para publicação. 
58. Sharma, R. K.; Bakhashi, N. N.; Can. J. Chem. Eng. 1991, 69, 1071.

59. Idem, R. O.; Katikaneni, S. P. R.; Bakhshi, N. N.; Fuel Process. Technol. 1997, 51, 101 .

60. Santos, F. R.; Ferreira, J. C. N.; Quim. Nova 1998, 21, 560.

61. Dandik, L.; Aksou, A.; Erdem-Senatalar, A.; Energy \& Fuels 1998, 12, 1148.

62. Quirino, R. L.; Tavares, A. P.; Peres, A. C.; Rubim, J. C.; Suarez, P. A. Z.; J. Am. Oil Chem. Soc. 2009, 86, 167.

63. Gonzalez, W. A.; Nunes, P. P.; Ferreira, M. S.; Martins, E. P.; Reguera, F. M.; Pastura, N. M. R.; Encontro De Energia No Meio Rural, Campinas, Brasil, 2000, disponível em http://www. proceedings.scielo.br/scielo.php?script=sci_arttext\&pid=MSC000 $0000022000000200047 \& \operatorname{lng}=$ en $\& n r m=a b n$, acessada em Dezembro 2008.
64. Brandão, R. F.; Quirino, R. L.; Mello, V. M.; Tavares, A. P.; Peres, A. C.; Guinhos, F.; Rubim, J. C.; Suarez, P. A. Z.; J. Braz. Chem. Soc. 2009, no prelo.

65. Suarez, P. A. Z.; Rubim, J. C.; Mundim, K. C.; BR pat. 0204019-0, 2002.

66. Gomes, J. R.; BR pat. $0500591,2005$.

67. Schafer, H.; Em Topics in current chemistry, Springer-Verlag: Stuttgart, 1990, vol. 152.

68. Goulart, M. O. F.; Schäfer, H.; J. Braz. Chem. Soc. 1999, 10, 153.

69. Kurihara, H.; Fuchigami, T.; Tajima, T.; J. Org. Chem. 2008, 73, 6888.

70. Resolução ANP N ${ }^{\circ} 15$, de 17/07/2006, Diário Oficial da União, 19/07/2006. 